\title{
Changes in cerebral cortex size are governed by fibroblast growth factor during embryogenesis
}

Flora M. Vaccarino, Michael L. Schwartz, Rossana Raballo, Jon Nilsen, Julianne Rhee, Ming Zhou, Thomas Doetschman, J. Douglas Coffin, Jason J. Wyland and Yu-Ting Elizabeth Hung

Nat. Neurosci. 2, 246-253 (1999)

On page 251, Table 5 incorrectly listed the number of FGF2-/- cells as $2.5 \pm 0.62$ million. The correct number is $12.5 \pm 0.62$ million. We regret the error.

\section{SOD1 mutants linked to amyotrophic lateral sclerosis selectively inactivate a glial glutamate transporter}

Davide Trotti, Andreas Rolfs, Niels C. Danbolt, Robert H. Brown Jr. and Matthias A. Hediger

Nat. Neurosci. 2, 427-433 (1999)

On page 428, Fig. 1 was labeled incorrectly. The correct figure is reproduced below.
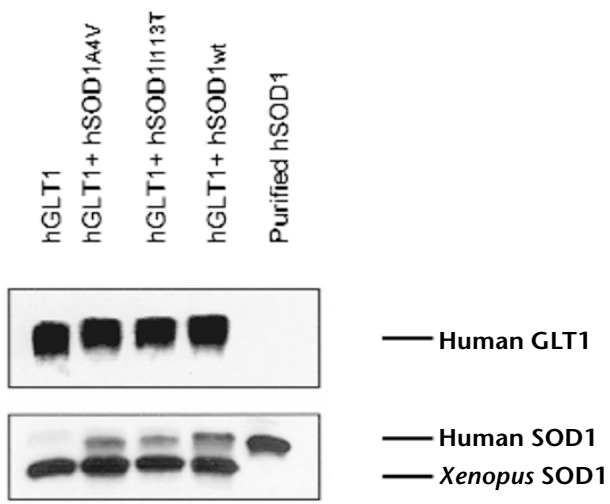

\section{Dendritic $I_{\mathrm{h}}$ normalizes temporal summation in hippocampal CA1 neurons}

Jeffrey C. Magee

Nat. Neurosci. 2, 508-514 (1999)

Because of an editorial error, the first sentence of the last paragraph on page 511 was incorrect. The sentence should read as follows:

By subtracting the EPSP trains evoked during $I_{\mathrm{h}}$ blockade from the control train, the time course of synaptic hyperpolarization induced by $I_{\mathrm{h}}$ deactivation was examined.

\section{Timing of cochlear feedback: spatial and temporal representation of a tone across the basilar membrane}

K. E. Nilsen and I. J. Russell

Nat. Neurosci. 2, 642-648 (1999)

Because of an editorial error, the first sentence of the Results section on page 642 was incorrect. The sentence should read as follows:

Tone-evoked basilar membrane displacements were measured with a laser diode interferometer focused to a $5 \mu \mathrm{m}$ spot with a depth of field of less than $2.3 \mu \mathrm{m}$, at up to 15 different locations across the width of the basilar membrane (Fig. 1c).

\section{Signaling myopia}

Kalyani Narasimhan

Nat. Neurosci. 2, 691 (1999)

The second sentence should read "If the shape of the eye produces a focal plane in front of the retina, the eye is myopic, and the image appears blurred." We regret the error. 